\title{
Knowledge, Practice and Attitude of Dentists towards Cone Beam Computed Tomography
}

\author{
Fatma Fayez Badr¹, Mohammed Abdulaziz Barayan², Fatima Mohammed Jadu 3 , Hanadi Mohammed Khalifa ${ }^{4}$ \\ 1,2,3,4 Department of Oral Diagnostic Sciences, King Abdulaziz University, Jeddah, Saudi Arabia.
}

\section{ABSTRACT}

\section{BACKGROUND}

Cone beam computed tomography (CBCT) was first introduced in 2008 and has since seen a tremendous growth in both private dental clinics and dental institutions. This has led to the normalization of CBCT use by general dentists. Therefore, it is essential to assess how and why general and specialist dentists use CBCT. The purpose of this study was to assess the knowledge, practice and attitude towards CBCT among general and specialist dentists working in the kingdom of Saudi Arabia.

\section{METHODS}

In this cross-sectional study, a questionnaire was electronically distributed via email and social media from October 2018 to September 2020. The self-administered questionnaire was divided into five segments: demographics, knowledge, current practice, training and attitude.

\section{RESULTS}

A total of 221 dentists filled the questionnaire including 85 general dentists and 135 post graduate students or specialists. The majority of dentists $(81.9 \%)$ demonstrated poor knowledge. Orthodontists and endodontists were most aware of CBCT terms. Most dentists (71.5 \%) have a CBCT unit in their practice. Only $34.8 \%$ received CBCT training, the majority of which was theoretical. A positive attitude was noted in 83.2 $\%$ of dentists by agreeing to a statement regarding CBCT justification.

\section{CONCLUSIONS}

Poor CBCT knowledge was evident in majority of dentists despite having CBCT in their practice. Dentists are highly aware of the importance of CBCT justification and professional interpretation; however, they lack basic knowledge and training related to this imaging modality. This highlights an institutional gap that policy makers should address in order to ensure the highest quality of patient care.
Corresponding Author: Dr. Hanadi Mohammed Khalifa, Assistant Professor, Department of Oral Diagnostic Sciences, Oral Radiology Division - Faculty of Dentistry, King Abdulaziz University, P.O. Box 21589, Jeddah, Saudi Arabia. E-mail: hmkhalifah@kau.edu.sa

DOI: $10.14260 /$ jemds/2021/691

How to Cite This Article: Badr FF, Barayan MA, Jadu FM, et al. Knowledge, practice and attitude of dentists towards cone beam computed tomography. J Evolution Med Dent Sci 2021;10(38):3413-3418, DOI: 10.14260/jemds/2021/691

Submission 20-05-2021, Peer Review 04-09-2021, Acceptance 11-09-2021, Published 20-09-2021.

Copyright (C) 2021 Fatma Fayez Badr et al. This is an open access article distributed under Creative Commons Attribution License [Attribution 4.0 International (CC BY 4.0)]

\section{KEY WORDS}

Cone Beam Computed Tomography; CBCT; Survey 


\section{BACKGROUND}

Cone-beam computed tomography is a three-dimensional imaging technique that has distinct advantages, such as reducing the radiation dose in comparison to multidetector computed tomography (MDCT), high spatial resolution, and fast scan times. ${ }^{1}$ CBCT has a wide range of applications in dentistry. These applications include dental implant treatment planning, determining the approximation of mandibular third molars to the mandibular canal, orthodontic treatment planning, temporomandibular joint assessments, and evaluating pathosis and dentoalveolar trauma. ${ }^{2}$ As a result of the increased demand for CBCT in dental practices, several organizations have issued position papers and recommendations on the use of CBCT for various indications as they pertain to different dental specialties. Evidence-based guidelines regarding the referral criteria, justification, and optimization of maxillofacial CBCT users have been developed. According to these guidelines, CBCT is indicated when conventional radiographs cannot answer the clinical question for which CBCT imaging is needed.3-5 Therefore, all CBCT requests must be customized and justified with risk versus benefit assessments for each patient. The recommendations based on the frequency of incidental findings mandate that a certified oral and maxillofacial radiologist (OMFR) is responsible for the interpretation of maxillofacial CBCT examinations. ${ }^{6}$

A limited number of studies have been published regarding the knowledge of dental graduates from different dental institutions about CBCT.7,8 These studies have found that most students have some knowledge about CBCT as an imaging modality. A national survey was undertaken in Norway to look at the use of CBCT in dental clinics and to assess dentist's experiences with it. ${ }^{9} \mathrm{~A}$ recent survey by Buchanan et al. was conducted to assess radiation safety measures, training, and interpretation of CBCT by general dentists, oral surgeons, and periodontists in Georgia, USA.10 The study highlighted educational voids related to, but not limited to radiation safety and interpretation.

CBCT was first introduced in 2008 and has since seen a tremendous growth in both private dental clinics and dental institutions. ${ }^{11}$ This has led to the normalization of CBCT use by general dentists, despite their lack of professional training. Therefore, it is essential to assess how and why general and specialist dentists use CBCT. To our knowledge, no previous wide-scale studies have investigated the current CBCT practices. Thus, the objective of this study was to investigate the basic knowledge, current practice, training, and attitudes toward CBCT among general and specialist dentists working in the kingdom of Saudi Arabia and to determine the gaps in knowledge and training. This will then guide the efforts to implement effective continuing education (CE) courses, suggest practical guidelines for CBCT use, and improve patient care.

\section{METHODS}

In this cross-sectional study, a questionnaire was electronically distributed via email and social media from
October 2018 to September 2020. All procedures followed were in accordance with the ethical standards of the responsible committee on human experimentation (institutional and national) and with the Helsinki Declaration. Data were obtained in the form of a structured, validated, selfadministered questionnaire, which was approved by the Research Ethics Committee at King Abdulaziz University, Faculty of Dentistry. Participants were informed of the aim of the study and were allowed to withdraw their data at any time without repercussions. For validation, the questionnaire was pre-tested on 10 dentists.

\section{Participants}

Based on the number of licensed dentists in the kingdom of Saudi Arabia (16887), the minimum required sample size to achieve $95 \%$ confidence level and $10 \%$ margin of error was 96. A total of 221 dentists filled the questionnaire. The target population was general dentists, residents, and specialists from Saudi Arabia. Post-graduate students (PGS) were included but undergraduate students were excluded. General dentists, residents, and specialists were contacted via email and WhatsApp application and were asked to distribute the Google form link to their colleagues. The link was sent to those working in the government sector as well as those in the private sector. The link included a message explaining the aim of the study and requested voluntary participation.

\section{Questionnaire}

The questionnaire was conceptualized in a focus group made of four OMFRs, then pre-tested using 10 dentists. Digital distribution of the questionnaire was done via emails and social media (WhatsApp). The English language written questionnaire was created using Google forms and divided into five segments: demographics ( 9 items), knowledge (11 items), current practice (11 items), training (4 items), and attitude ( 2 items).

To ensure privacy and anonymity, no personal information was collected. Demographic questions recorded data concerning age, years of experience, educational level, year of residency training, specialty, country from which the highest degree was obtained, country of practice, practice sector, and name of the institution.

The knowledge questions included five multiple choice questions assessing the level of awareness regarding the most common CBCT terminology. There were also six multiple choice questions about the relationship between resolution and dose, the difference between CBCT and MDCT, the smallest voxel size, and the field of view available in the market.

The six knowledge questions were scored out of 6 points, a score of 1 was assigned if the answer was correct, while a score of 0 was given if the answer was incorrect. The level of knowledge was then categorized into poor (0-2), fair (3-4), or good (5-6). Other close-ended questions included in the remaining segments are outlined in (Appendix 1).

\section{Data Analysis}

Statistical analyses were done using IBM Statistical Package for Social Sciences (SPSS statistics for Windows, version 26.0) (IBM Corp., Armonk, NY, USA). Associations between 
demographic variables, awareness, knowledge, training, practice, and attitude were examined.

\section{RESULTS}

A total of 221 participants completed the questionnaire, including 86 general dentists and 135 PGS or specialists. It is difficult to calculate unit response rate when using web-based surveys. ${ }^{12}$ However, partial non-response rate, where participants leave some questions unanswered, was $44 \%$. The response rate of questionnaire items varied from $56 \%$ to 100 $\%$, among participants. The sample demographic data is summarized in Table 1.

\begin{tabular}{|c|ccc|}
\hline & Variables & Frequency $(\mathbf{n}=\mathbf{2 2 2})$ & $\%$ \\
& Younger than 30 & 83 & 37.7 \\
Age & $30-39$ & 109 & 49.5 \\
& $40-49$ & 15 & 6.8 \\
& $50-59$ & 8 & 3.6 \\
Years of & 60 and older & 2 & 0.9 \\
experience & 15 years and more & 16 & 7.3 \\
& 10 to less than 15 years & 20 & 9.1 \\
& 5 to less than 10 years & 75 & 34.1 \\
& Less than 5 years & 109 & 49.5 \\
& Endodontics & 26 & 11.8 \\
& General dentistry & 85 & 38.6 \\
& Oral and maxillofacial radiology & 3 & 1.4 \\
& Oral and maxillofacial surgery & 5 & 2.3 \\
& Oral medicine & 12 & 5.5 \\
& Orthodontics & 29 & 13.2 \\
& Pedodontics & 14 & 6.4 \\
& Periodontics & 13 & 5.9 \\
& Prosthodontics & 14 & 6.4 \\
& Restorative dentistry & 19 & 8.6 \\
\hline & Table 1. Demographic Data of the Surveyed Dentists & \\
\hline
\end{tabular}

\begin{tabular}{|c|c|c|c|}
\hline & \multirow{2}{*}{ CBCT Knowledge } & \multicolumn{2}{|c|}{ Semi-Adjusted Model } \\
\hline & & OR & $95 \%$ CI \\
\hline \multirow{4}{*}{ Age } & $30-39$ & $7.62 * *$ & {$[3.65,11.58]$} \\
\hline & $40-49$ & $9.67^{* *}$ & {$[2.47,17.27]$} \\
\hline & $50-59$ & $16.44^{*}$ & {$[5.23,27.65]$} \\
\hline & 60 and older & 15.61 & {$[-6.77,37.98]$} \\
\hline Experience & 5 to $<10$ years & $-2.64^{*}$ & {$[-5.21,-0.07]$} \\
\hline \multirow{3}{*}{ Educational level } & $\begin{array}{l}\text { Assistant professor/ } \\
\text { specialist/ consultant }\end{array}$ & $-11.78^{* *}$ & {$[-16.55,-7.01]$} \\
\hline & Associate professor & -8.47 & {$[-27.08,10.14]$} \\
\hline & Professor & $-21.66^{*}$ & {$[-42.27,-1.06]$} \\
\hline \multirow{3}{*}{ Specialty } & Endodontics & $13.60^{* *}$ & {$[5.03,22.17]$} \\
\hline & OMF surgery & $13.99 *$ & {$[2.19,25.80]$} \\
\hline & Oral medicine & $11.98^{* *}$ & {$[4.20,19.76]$} \\
\hline $\begin{array}{c}\text { Do you outline } \\
\text { risks/benefits of CВCT? }\end{array}$ & Always & $4.72^{* *}$ & {$[1.41,8.03]$} \\
\hline $\begin{array}{l}\text { Do you examine the } \\
\text { entire CBCT volume? }\end{array}$ & Always & $10.62^{* *}$ & {$[4.01,17.24]$} \\
\hline \multicolumn{4}{|c|}{$\begin{array}{c}\text { Table 2. Ordinal Regression Odds Ratios for Factors Associated with } \\
\text { CBCT Knowledge, among Dentists, after Adjusting for Age, Years of } \\
\text { Experience, Educational Level, Specialty and CBCT Training, (n=173). } \\
\text { Missing Values Were Treated as Missing }\end{array}$} \\
\hline \multicolumn{4}{|l|}{ value $*^{*} \leq 0.05, * * \leq 0.01$} \\
\hline
\end{tabular}

\section{CBCT Knowledge}

Most of our participants (82 \%) demonstrated poor knowledge regarding CBCT basic knowledge. Figure 1 illustrates the overall CBCT knowledge of dentists. After controlling for age, years of experience, and educational level, three specialties were more likely to have better CBCT knowledge. These specialties were endodontics, oral and maxillofacial surgery, and oral medicine. Additionally, age, experience, educational level, and always outlining the risk/benefits of CBCT to patients were all statistically important factors associated with enhanced knowledge (Table 2).
The degree of awareness regarding the five most common CBCT terms is illustrated in Figure 2. Specialists that were statistically more likely to be aware of the term "field of view" (FOV) were endodontists (OR: 3.00; $95 \% \mathrm{CI}: 1.31,4.69$ ) and orthodontists (OR: 1.46; 95 \% CI: 0.28, 2.65). Endodontists were the only specialists significantly more aware of the term "spatial resolution" when compared with the other specialists (OR: 2.35; 95 \% CI: 0.01, 0.90). Prosthodontists were statistically more likely to never have heard the term "image noise" when compared to other specialties (OR: 1.83; $95 \% \mathrm{CI}$ : $0.84,46.57)$.

\section{CBCT Practice}

Seventy-two percent of the respondents had CBCT units in their practice, $75 \%$ of which had received some sort of CBCT training. The majority (72 \%) did not know the highest resolution their CBCT units could provide in their workplace. Sixty-one percent of respondents referred up to five patients per month. There was great variability in outlining the possible risks/benefits of CBCT to patients before the scans were performed, ranging from never (19.5\%) to always (31.7 $\%)$. Moreover, $85 \%$ of those that answered "never," did not receive any CBCT training. The most common reason given for not outlining the risks/benefits to patients was a "lack of knowledge" (31\%). Only half of those that self-interpret the CBCT images had received CBCT training. Forty-eight percent never/rarely evaluated the entire imaged volume despite receiving CBCT training. The most common reason for not referring to an OMFR was "difficulty in communication and sending the cases" (43\%), followed by "I don't know an OMFR" (18\%), and "as a dentist, I have enough knowledge to efficiently interpret a CBCT" (14\%). Forty-eight percent of our sample rarely/never use virtual treatment planning software or surgical guides.

\section{CBCT Training}

Four types of CBCT training were identified, postgraduate courses attended at a dental institution, commercial courses given by manufacturers and vendors, CE courses at professional meetings, and online courses. However, $65 \%$ of the participants had not received any form of training. The type of training heavily influenced the CBCT knowledge results, as evidenced by the fact that CBCT training alone was not associated with higher odds of CBCT knowledge in the adjusted regression model. Knowledge was better among those that attended a CBCT postgraduate course $(n=22)$. Of those who attended CBCT CE courses, 6 out of 7 respondents still had poor knowledge. All participants that received online CBCT training also had poor knowledge. When asked about recommendations for future CBCT courses, most participants suggested the following topics: CBCT normal anatomy, image acquisition, image planning software, interpretation, and report writing. Approximately $91 \%$ of the participants who were interested in CBCT CE courses were 39 years or younger. Moreover, general dentists were more interested in future CBCT CE courses than all other specialties. 


\section{CBCT Attitude}

Regarding the agreement with the statement that the CBCT should only be used when conventional radiographs cannot answer the clinical question for which the CBCT was requested, the two most common answers were "agree" and "strongly agree" (83 \%) across all dental specialties. Regarding making the interpretation of CBCT scans legally mandated by an OMFR, the two most common answers were also "agree" and "strongly agree" (75 \%).

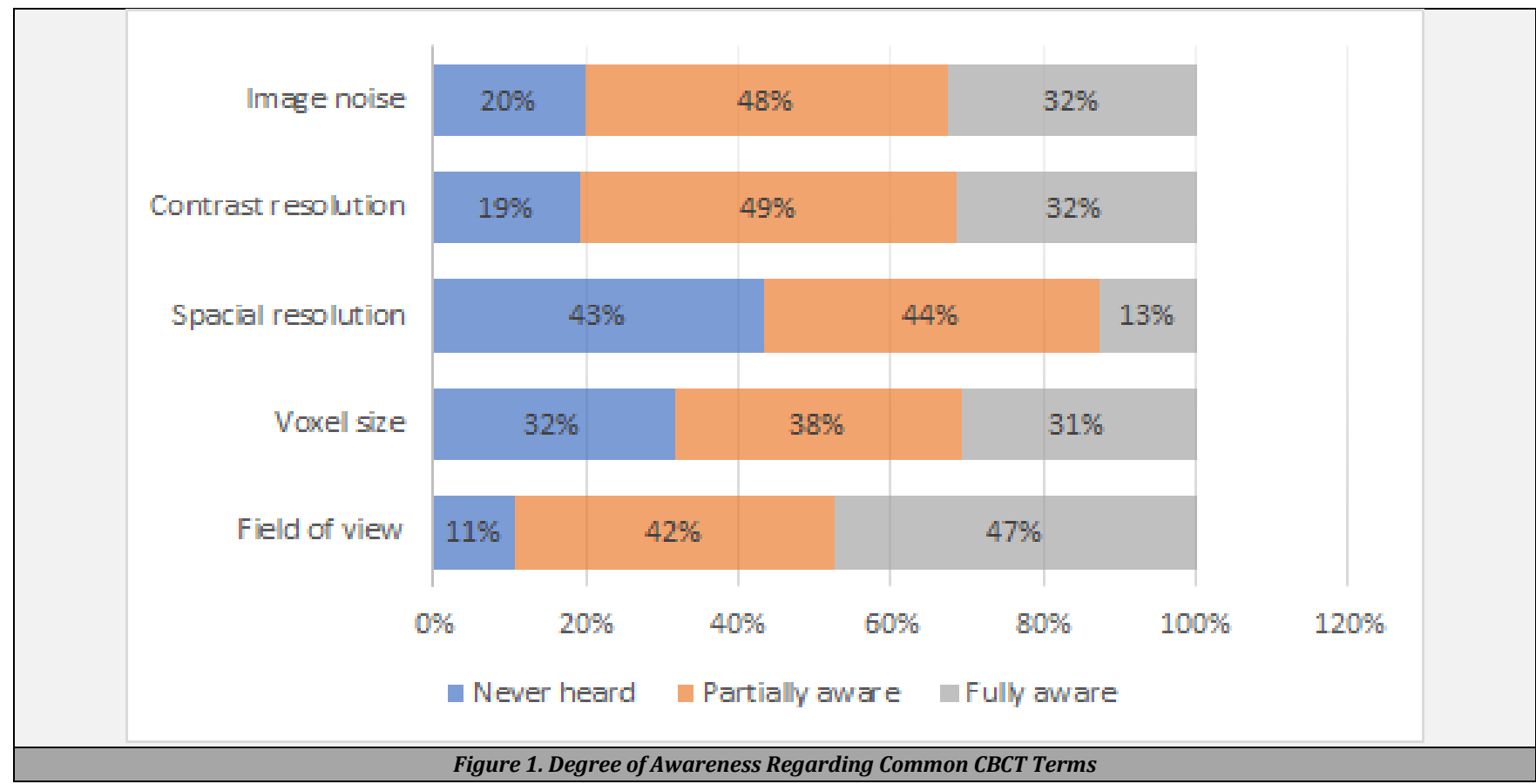

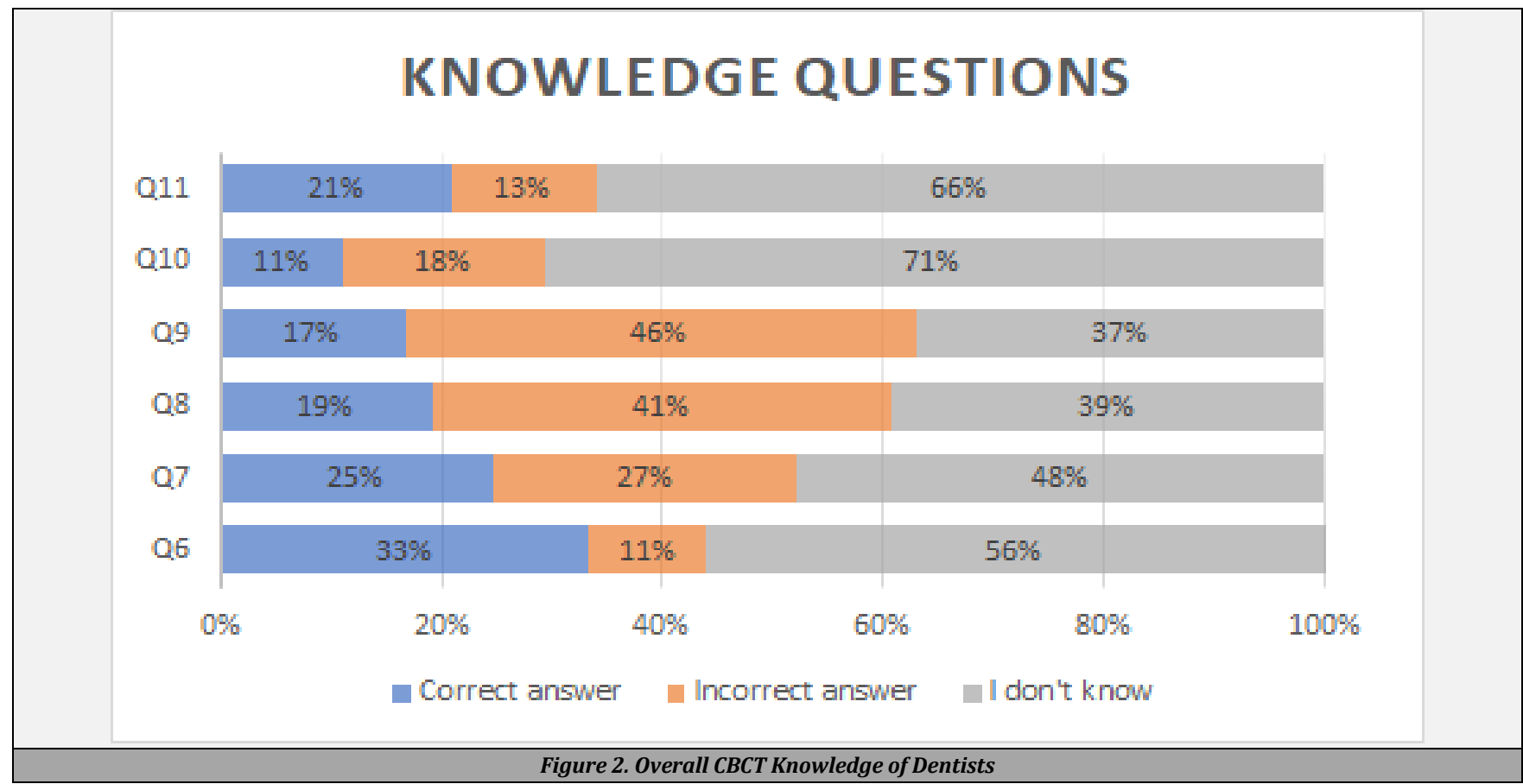

\section{DISCUSSION}

The results of this study indicated a gross lack of knowledge regarding basic CBCT concepts and terms. This is concerning since over $72 \%$ of the sample have CBCT units in their workplace and $74 \%$ of them refer their patients for CBCT imaging. Referring patients for this imaging modality requires some basic knowledge and adequate training. ${ }^{13}$
Although Al Noaman and El Khateeb studied the attitudes toward and knowledge of CBCT in Al Madinah Al Monwarah, Saudi Arabia, ${ }^{14}$ this study was restricted to a single novel academic institution and only a small sample of students were included in the study. Similar to our results, Yeung et al. found limited CBCT knowledge among dentists in Hong Kong. ${ }^{15}$ We found that endodontists and orthodontists were significantly more aware of CBCT terms than other specialists. This is plausible since these two specialties often require volumetric 
imaging to detect abnormalities, such as accessory root canals or impacted canines. ${ }^{16,17}$

Similar to our findings, a study conducted in the middle east has also found that years of experience did not impact CBCT knowledge.11 This is possibly because the years of experience were focused on other areas that did not involve CBCT training. This same study found that the level of education improved CBCT knowledge, which was not what we found. This may be explained by the fact that we studied a larger sample.

Dentists from several specialties were comfortable with self-interpretation of the imaged volume, yet over $48 \%$ of the participants rarely or never evaluated the entire CBCT volume. Incidental findings in CBCT images have been reported extensively in the literature, some of which occur in the base of the skull and require prompt referrals.6,18-20 Without professional training involving the interpretation of cross-sectional imaging, it is easy to miss significant findings. The results indicated that the main barrier facing dentists, which hinders the referral of CBCT cases to an OMFR, was the difficulty in communication and sending cases. This barrier was present regardless of whether the dentist worked in the governmental or private sector. A potential solution to overcome this barrier involves the implementation of oral and maxillofacial teleradiology services. ${ }^{21,22}$

Most of our participants did not receive any CBCT training. The European Academy of Dentomaxillofacial Radiology states that there are two levels of CBCT training. ${ }^{13}$ First, the basic level of training that allows prescription and patient referrals for CBCT imaging. The second level of training allows interpretations of CBCT studies. Another study also found that majority of dental practitioners received little to no CBCT training. ${ }^{13}$ The fact that training was not associated with an enhanced knowledge may be due to the limited training and theoretical nature of the training that these dentists received. The expertise of the trainer also has a significant influence. After three hours of training by an OMFR, Ahmad et al. found that training orthodontists and orthodontic residents reduced the false positive and false negative identification of incidental findings in CBCT by one third. ${ }^{23}$

Majority of our participants had a positive attitude and were highly aware in terms of justification of CBCT studies and mandating an OMFR interpretation for all CBCT studies acquired for different purposes, similar to another recent study. ${ }^{11}$ This previous study found that over $90 \%$ of dentists are interested in receiving CBCT training. Similarly, other dentists in Saudi Arabia, Jordan, and Egypt have also recommended incorporating $\mathrm{CBCT}$ training in undergraduate dental curricula. ${ }^{11}$

\section{CONCLUSIONS}

Dentists from Saudi Arabia are highly aware of the importance of CBCT justification and professional interpretation. However, they lack basic knowledge and training related to imaging modality. Difficulty in communication is the main barrier stopping dentists from referring cases to an OMFR. This highlights an institutional gap that policy makers should address in order to ensure the highest quality of patient care.

\section{Limitations of This Study}

This study was limited by biased coverage because majority of respondents were affiliated with King Abdulaziz University. Also, the number of respondents from each dental specialty was disproportionate. The exact non-response rate could not be calculated. Other limitations include those inherent in cross-sectional design studies. Also, the influence of sex was not evaluated in the regression model as it was not part of the data collected in the questionnaire.

Data sharing statement provided by the authors is available with the full text of this article at jemds.com.

Financial or other competing interests: None.

Disclosure forms provided by the authors are available with the full text of this article at jemds.com.

\section{REFERENCES}

[1] Corns RA. Advantages and limitations of cone beam computed tomography. J Indiana Dent Assoc 2016;95(3):24-6.

[2] Venkatesh E, Elluru SV. Cone beam computed tomography: basics and applications in dentistry. J Istanb Univ Fac Dent 2017;51(3 Suppl 1):S102-S21.

[3] American Academy of Oral and Maxillofacial Radiology. Clinical recommendations regarding use of cone beam computed tomography in orthodontics. (Corrected). Position statement by the American Academy of Oral and Maxillofacial Radiology. Oral Surg Oral Med Oral Pathol Oral Radiol 2013;116(2):238-57.

[4] Special Committee to Revise the Joint AAE/AAOMR Position Statement on use of CBCT in Endodontics. AAE and AAOMR Joint Position Statement: use of cone beam computed tomography in endodontics 2015 update. Oral Surg Oral Med Oral Pathol Oral Radiol 2015;120(4):50812.

[5] Tyndall DA, Price JB, Tetradis S, et al., Position statement of the American Academy of Oral and Maxillofacial Radiology on selection criteria for the use of radiology in dental implantology with emphasis on cone beam computed tomography. Oral Surg Oral Med Oral Pathol Oral Radiol 2012;113(6):817-26.

[6] Dief S, Veitz-Keenan A, Amintavakoli N, et al. A systematic review on incidental findings in cone beam computed tomography (CBCT) scans. Dentomaxillofac Radiol 2019;48(7):20180396.

[7] Shah PH, Venkatesh R. Dental students' knowledge and attitude towards cone-beam computed tomography: an Indian scenario. Indian J Dent Res 2016;27(6):581-5.

[8] Kamburoglu K, Kursun S, Akarslan ZZ. Dental students' knowledge and attitudes towards cone beam computed tomography in Turkey. Dentomaxillofac Radiol 2011;40(7):439-43.

[9] Hol C, Hellen-Halme K, Torgerson G, et al. How do dentists use СВCT in dental clinics? A Norwegian nationwide survey. Acta Odontol Scand 2015;73(3):195-201.

[10] Buchanan A. Thachil K, Haggard C, et al. Predoctoral and postdoctoral education on cone-beam computed tomography. J Evid Based Dent Pract 2017;17(4):310-16.

[11] Zain-Alabdeen E, El Khateeb SM. Comparison of knowledge and perspectives toward cone-beam 
computed tomography among dentists in three Middle East regions: a cross-sectional study. Saudi Journal of Oral Sciences 2018;5(1):3-10.

[12] Manfreda KL, Berzelak N, Vehovar V. Nonresponse in Web Surveys. In: Lovric M, edr. International Encyclopedia of Statistical Science. Berlin, Heidelberg: Springer 2011. https://doi.org/10.1007/978-3-642-04898-2_43

[13] Brown J, Jacobs R, Jaghagen LE, et al. Basic training requirements for the use of dental CBCT by dentists: a position paper prepared by the European Academy of DentoMaxilloFacial Radiology. Dentomaxillofac Radiol 2014;43(1):20130291.

[14] Al Noaman RF, El Khateeb SM. Knowledge and attitude of cone beam CT- A Questionnaire based study among Saudi dental students. Journal of Advances in Medicine and Medical Research 2017;19(4):1-10.

[15] Yeung AWK, Tanaka R, Jacobs R, et al. Awareness and practice of 2D and 3D diagnostic imaging among dentists in Hong Kong. Br Dent J 2020;228(9):701-9.

[16] Kapila SD, Nervina JM. CBCT in orthodontics: assessment of treatment outcomes and indications for its use. Dentomaxillofac Radiol 2015;44(1):20140282.

[17] Patel S, Brown J, Pimentel T, et al. Cone beam computed tomography in endodontics - a review of the literature. Int Endod J 2019;52(8):1138-52.
[18] Barghan SM, Arashlow TM, Nair MK. Incidental findings on cone beam computed tomography studies outside of the maxillofacial skeleton. Int J Dent 2016;2016:9196503.

[19] Khalifa HM, Felemban OM. Nature and clinical significance of incidental findings in maxillofacial conebeam computed tomography: a systematic review. Oral Radiol 2021.

[20] Allareddy V, Vincent SD, Hellstein JW, et al. Incidental findings on cone beam computed tomography images. Int J Dent 2012;2012:871532.

[21] Yang J, Angelopoulos C, Mallya S, et al. American Academy of Oral and Maxillofacial Radiology executive opinion statement on teleradiology. Oral Surg Oral Med Oral Pathol Oral Radiol 2016;122(4):509-10.

[22] Almazrooa SA, Mansour GA, Alhamed SA, et al. The application of teledentistry for Saudi patients' care: a national survey study. J Dent Sci 2021;16(1):280-6.

[23] Ahmed F, Brooks SL, Kapila SD. Efficacy of identifying maxillofacial lesions in cone-beam computed tomographs by orthodontists and orthodontic residents with thirdparty software. Am J Orthod Dentofacial Orthop 2012;141(4):451-9. 